Artigos

\author{
Claudia Maria Finamore \\ Círc ulo Psic ana lítico do Rio de J a neiro \\ João Eduardo Coin de Carvalho
Universidade Paulista
}

\title{
Mulheres candidatas: relações entre gênero, mídia e discurso
}

\begin{abstract}
Resumo: Tendo como pano de fundo a sobreposição das presenças da mulher e do político nas candidaturas a cargos públicos, neste artigo discutimos o peso da mídia na influência sobre a escolha dos eleitores e a posiç ão destescomo intérpretes dessas mensagens midiátic as. Assumindo um entendimento que relativiza o poder da mídia, indicamos como a idéia de discurso de (e sobre)gênero pode ser compreendido como media dor dessa influência. Embora pesquisas indiquem que a presença da mulher na mídia como candidata, transforma da em um produto de marketing, tendem a desqualificá-la, esses efeitos a penas acompanham o estereótipo da mulher restrita à cena privada, alimentado por um discurso social que identifica o lugar da mulher como sendo o lar, longe, portanto, do espaço público. A mídia, assim, além de sua responsabilidade pela instalação desse lugar de mulher, a tua pela sua manutenção. Concluímos que a participação política das mulheres se apresenta intimamente ligada a como elas são representadas no senso comum, indicando que uma mudança da partic ipação polític a feminina passaria pela mudança nos discursos hegemônicos sobre as mulheres, discursos esses que a travessam os indivíduos e os grupos socia is.
\end{abstract}

Palavras-chave: gênero; política; eleições; discurso; mídia.

Copyright $\propto 2006$ by Revista Estudos Feministas.

${ }^{1}$ Luis Felipe MIG UEL, 2000.

\section{Influência da mídia e o lugar do público}

A influência da mídia sobre a opinião pública causa interesse tanto à população quanto aos cientistas sociais. Época de eleições para cargos políticos costuma trazer à tona ta I discussão, quando a sugestiona bilidade dos eleito res pelos meios de comunicação é questionada. Embora a literatura que trata do deba te polític 0 , ou a inda, os próprios cientistas sociais, nem sempre tenham considerado suficientemente o poder da mídia, muitas vezes relegandoa a uma posição coadjuvante, ${ }^{1}$ a discussão das relações entre mídia e prática política no Brasil tem recebido nos últimos a nos importantes contribuições. 
${ }^{2}$ AZAMBUJ A, 1987.

${ }^{3}$ Vic tor BLANCO, 1999

${ }^{4}$ MIGUEL, 1999

${ }^{5}$ MIG UEL, 2002.
Para Darcy Aza mbuja, ${ }^{2}$ tendo em vista que a cultura de massas obriga o indivíduo a perder ou a não formar uma imagem de si mesmo diante da sociedade, praticando um reforço das normas socia is e promovendo o conformismo social, a mídia a tua sobre o indivíduo de forma a manipular suas escolhas e comportamentos políticos. Nessa perspectiva, os sujeitos não teria m mesmo a noção de que são influenciados pelos meios de comunicação de massa, desenvolvendo, por exemplo, uma postura passiva diante das notícias veiculadas pelos jorna is ou programas de TV, e paulatinamente anulando qualquer posicionamento crítico em relação à mensagem. Assim, pa ra esse autor, os indivíduos e os grupos socia is não são ma is d o que meros receptores que a c eitam op iniões prontas que vêm dos meios de comunicação e, sem cogitar como essas mensagens são constituídas em outras instâncias, aderem a tais idéias como se elas fossem de fato suas próprias produções.

Em uma posição menos crítica, tem-se também considerado que os meios de comunic ação abrangem lóg ic as instituc iona is contra ditórias. ${ }^{3}$ Constituem, por um la do, um negócio e um recurso de influência polític o-social, mas não podem pema necerind iferentes à op inião pública pordependerem da sua audiência. A formação de opiniões por intermédio dos meios de comunic ação, portanto, se dá a tra vés de um exercíc io de liberda de instituciona liza da que pode modificar as opiniões que se desenvolvem no decorrer do tempo.

Mas se a mídia tem sido tradicionalmente uma 'presença invisível' na literatura política, a influência dos grandes monopólios de informação, por outro lado, é sensível nas ca mpanhas polític as brasileiras, qua ndo estes demonstram um poder de articulação e definição da agenda política sem paralelo. ${ }^{4} \mathrm{Em}$ trabalho recente, Luis Felipe Miguel $^{5}$ tra ta dos efeitos dos meios de comunic ação sobre a prátic a política e defende que os indivíduos, mesmo que não apenas e todo o tempo, são uma caixa de repercussão dos discursos construídos pelas elites. Em a lguma medida eles selecionam, interpretam e enqua dram as informações recebidas de acordo com os códigos que possuem e que não vêm necessariamente do campo midiático, mas pertencem a o campo político. Embora localize na mídia um importante fator de habilitação de c apita is políticose de definição da a genda política, o a utor entende, no entanto, que a mídia não constitui as instituiçõespolíticas, como o parla mento, o poderexecutivo, os partidos ou as eleições, de tal forma que o campo político e o midiático estão necessariamente separados. Embora sejam importante peça de influência no jogo 
${ }^{6}$ J ohn THOMPSON, 1989.

7 J oão Edua rdo CARVALHO, 1999.

${ }^{8}$ Rogério SCHMITT, Leandro CARNEIRO e Karina KUSCHNIR, 1999.

9 Stephen ANSO LABEHERE, Roy BEHR e Shanto IYENGAR, 1993. polític o, não se pode dizer que os meios de comunic ação dominem esse campo. Nesse caso, a importância da mídia não estaria apenas na construção dos discursos, mas na sua força de reconhecimento como chave para a conquista do capital político.

Consideramos, em uma perspectiva próxima a esta que relativiza o poderda mídia, que falar em a lienação é tratar de um confronto de discursos. ${ }^{6}$ Essa concepção abarca tanto a crítica à determinação dos meios de comunicação de massa quanto a idéia de que as mensagens veiculadas a través deles não alcançam um espaço vazio, mas um meio vivo, com características próprias, que transforma e interpreta a mensagem. A partir dessa concepção ta mbém se poderá falar em diferentes forç as a gind o sobre os ind ivíduos, diferentes disc ursos, nem sempre fa cilmente conta bilizá veis. Construíd os na s rela ções cotidianas face a face e/ou através de relações virtua is, possíveis pela contínua expansão dos meios de comunic a ção de massa, esses discursos estã o a ssocia dos às diferentes categorias socia is que dema rcam o território social, como, por exemplo raça, religião, nacionalidade ou gênero, cobrindo não apenas os grupos dominantes da sociedade como também aqueles a que chamamos genericamente de excluídos. ${ }^{7}$

As escolhas feitas pelos indivíduos e pelos grupos socia is com suas histórias e existências peculia res são pautadas, assim, não apenas pela pura racionalidade ou pela absoluta emoção, mas também pela maneira como são a travessados por esses diferentes discursos. No confronto entre eles está guardada a tensão entre razão e afeto, palavras e imagens, e estão presentes as quase sempre encobertas rela ções de poderque oscarac terizam.

\section{Televisão e propaganda política na sociedade do imediatismo}

Entre os meios de comunicação de massa, a televisão tem sido considerada como um dos principa is formadores de opinião quando se fala em campanhas eleitorais, especialmente no caso do Brasil, onde a propaganda eleitoral gratuita possui uma enorme importância na escolha de candidatosa cargos públicos. ${ }^{8}$ Numa sociedade em que os indivíduos gastam cada vez mais tempo em frente à televisão do que aquele gasto com os relacionamentos sociais face a face, ela é um importante canal de condicionamento cultural da população, provendo, especialmente a partir da divulgação de notícias, muito daquilo que orienta os julgamentose as esc olhas dos eleitores. ${ }^{9}$ Deve-se levar em 
${ }^{10}$ MIGUEL, 1999.

${ }^{11}$ SC HMITT, CARNEIRO e KUSC HNIR, 1999.

${ }^{12}$ SC HMITT, CARNEIRO E KUSC HNIR, 1999.

${ }^{13}$ AZAMBUJ A, 1987.

${ }^{14}$ MIGUEL, 1999. conta que a notícia não se ocupa necessariamente com o fato, e sim com o detalhe que poderá ser mais a traente ao telespectador. Assim, a propaganda política no Brasil tem sido elaborada com esse mesmo propósito, o que a cara c terizaria ma is como uma ação de marketing do que informa tiva. ${ }^{10}$

No Brasil, a propaganda política gratuita na TV é um dos principa is veículos midiáticos utiliza dos pelos partidos polític os em épocas de eleição. Veiculada nos meses que antecedem as eleições, a tra vés dela os partidos políticos organizam a participação de seus candidatos com conseqüências signific a tivas sobre a imagem pública e o desempenho dos mesmos nas eleições. ${ }^{11}$ As campanhas polític as veic ula das a tra vés desses prog ra mas sã o ca pazes de interferir na opinião do eleitora do e no resultado das umas. As preferências por candidatos podem, por conta disso, sofrer mudanças especialmente durante o período de campanha eleitoral, de modo que o resultado de uma eleição pode ser alterado como efeito da propaganda eleitoral a té o final da disputa. Tais programas são vistos, no todo ou em parte, por todos os eleitores durante as semanas de campanha, fazendo da propaganda eleitoral gratuita uma das três fontes de informação política mais importantes para o eleitor, sendo fundamentais para a decisão do voto. ${ }^{12}$

Ating indo todo o público, sem discriminação, uma vez que é veiculada em toda a rede televisiva nacional, ela cria, entretanto, a impressão de ser direciona da a cada telespec ta dor ind ivid ua Imente. Rep rod uzind o uma conversa face a face, a imagem do candidato procura provocarno telespectador um sentimento de intimidade. A propaganda política também utiliza o tom emocional no discurso, buscando a ting ir os sujeitos em sua sesperanç as, a mbições, desilusões, preconceitos e medos. É desse modo que o discurso político é utilizado pelos governos e partidos polític os, criando correntes de opinião, suscitando desejos coletivos, distraindo, captando e dirigindo a atenção da população. ${ }^{13}$ Através de técnicas comerciais, a propaganda política 'vende' uma imagem do candidato e, atrelada à questão da sugestionabilidade, indica um modo de percepção dos polític os pelos telespectadores.

Migue ${ }^{14}$ sugere que um dos elementos crític os na disputa política é a criação de representações sobre os problemas, as crises, a dinâmic a polític a e, enfim, sobre os próprios candidatos. Para esse autor, a capacidade de disseminação de significados quanto à realidade social, isto é, desses discursos, está contemporaneamente concentrada na mídia, indicando que o impacto político dos conteúdos difundidos pela mídia não pode ser 
${ }^{15}$ Cecília COIMBRA, 2001.

${ }^{16}$ CARVALHO, 2002. ignorado. A longo prazo, trata-se de um impacto presente em diferentes tipos de programação, desde aquelas dedicadas à informação a té os programas de entretenimento. A curto prazo, a mídia informativa é especialmente importante, já que ela se apresenta como uma fonte de formecimento dos recursos que os eleitores dispõem antes de escolherem seus candidatos. Assim, aquilo que a mídia, no caso brasileiro, especialmente a míd ia televisiva, veicula ou deixa de veicular é signific a tivo do ponto de vista da percepção da realidade social que está acessível à população.

De modo geral, o próprio comportamento da mídia sofre influências, desde a ação do mercado a té a formação sócio-educacional dos profissionais da área. Adicione-se a esse cenário o fato de $90 \%$ da comunicação social brasileira ser controlada por apenas nove famílias, o que caracteriza um verdadeiro monopólio que intervém abertamente em questões diversas, de sociais e econômicas a políticas. Atra vés da hierarquização de temas, selecionando o que deve, ou não, ser do conhecimento público, e decidindo o que deve ser discutido, debatido ou pensado, esse monopólio age geralmente orientando o fluxo de informações para os desfechos que the interessa. ${ }^{15}$

É preciso ainda situar essa presença da mídia num contexto em que se enfatizam a instantaneidade, a descartabilidade, o ganho a curto prazo e a rapidez, carac terístic as de uma socieda de onde tudo é desc a rtável, pois se toma rapidamente obsoleto. Nesses termos, a construção e manutenção de imagens identitá rias, como a imagem de um político competente e confiável, vai se dar a tra vés da associação dos indivíduos a determinados traços, como roupas, a utomóveis, idéias, ou mesmo gêneros.

De fato, segundo Carvalho, ${ }^{16}$ numa sociedade em que os grupos socia is estão associados a marcas que não necessitam obrigatoriamente de um estofo relacional, isto é, marcasque são construída sà revelia de relações socia is face a face, seusvaloressão excessivamente dependentes da sua presença pública, especialmente a tra vés da mídia. o que implica ser um político, ou uma mulher, portanto, está sendo veiculado através de discursos que nos a tra vessam e constituem o luga rque essa sma rc a s oc upa m no universo de marcas identitárias disponíveis no jogo social.

A mutabilidade e a suscetibilidade dessas marcas identitárias à influência da mídia estão no peso de sua construção mais como categorias socia is e menos como grupos organic amente constituídos. Essas imagens não estão a lic erçadas a penas nas rela ções cotidianas face a 
${ }^{17}$ CARVALHO, 2002.

${ }^{18}$ Caroline HELDMANN, Susan CARROL e Stephanie OLSON, 2000.

19 CONWAY, STEUERNAGEL e AHERN, 1997.

${ }^{20}$ Mic hele SWERS, 2001. face, mas ta mbém são controla das pelas relações virtua is entre pessoas que se 'encontra $\mathrm{m}$ ', via de regra, através dos meios de comunic ação de massa. A fra gilida de dessas identidades não as faz menos efetivas, mas extremamente dependentes das ações que se produzem sobre sua dimensão imagética, e que tem nos meios de comunica ção um de seus vetores ma is importantes. Nesse sentido, o valor que oferecemos a os indivíduos, como os reconhecemos e como os entendemos nos relacionamentos cotidia nos podem ser compreendidos a tra vés das c a teg oria s so c ia is à s qua is os remetemos, c ujos signific a dos e valores são construídos e difundidos também por influência e a tra vés da mídia. ${ }^{17}$

O mesmo princípio está em jogo quando nos posicionamos em uma escolha, como no caso de eleições para cargos públicos. Aqui, somada aos determinantes ideológic os e estrutura is, a maneira como identific amos os candida tose como reconhecemosasmarcas que osfazem filiados a diferentes grupos sociais, também, orienta para a escolha de uma determinada imagem, daquilo que consideramos ser o melhor ou ma is a dequado candidato. Ou candidata.

\section{Mulheres candidatas, a mídia e o espaço privado}

Os estudos sobre a participação política das mulheres e a maneira como elas têm sido representadas pelos meios de comunic ação e pelos eleitores oferecem a lguma s p istas pa ra se entender as dific uld a des envolvidas em uma participação polític a feminina ma is efetiva. ${ }^{18}$ Entre outras indicações, Marga reth Conway, Gertrude Steuernagel e David Ahern ${ }^{19}$ apontam para as desvantagens públicas dessa falta, já que as mulheres teriam uma agenda política e um tra to com a res pública claramente diferenciados daqueles tipicamente masculinos. Mulheres ocupando cargos públicos leg isla tivos, por exemplo, têm sistema tic a mente dirig id o seus interessespara temasfeministas, formando frentes de defesa dasmulheres, seja em relação à violência contra a mulher, direitos reprodutivos ou saúde da mulher. ${ }^{20}$

Sobre as razões que explicariam as diferenças de gênero na orientação política, esses autores explicam que meninos e meninas tendem a ser educados de maneira diferente. Os resultados dessa diferença, antes de a pontar posic ionamentos ma is à esquerda ou à direita do espectro político, alcançam entendimentos sobre se as mulheres devem, por exemplo, ter a mesma participação política que os homens ou se 'o lugar das mulheres é em casa'. A 
${ }^{21}$ Barba ra BURRELL, 1994.

22 BURREL, 1994, p. 15.

${ }^{23}$ Mark Stephen LEEPER, 1991.

${ }^{24}$ Virg inia SAPIRO, 1982. educação diferencia da cobre um terreno social a mplo que passa pela questão da partic ipação política, masalcança as diferenças entre como homens e mulheres são tratados perante a lei ou o trabalho, em um processo contínuo de discriminação de gênero que se alimenta de orientações religiosas, assim como da maneira como as mulheres se vêem ou não liga dasa o grupo/categ oria social "mulheres". Pesquisas têm sistematicamente mostrado que, enquanto a aceitação das candidatas mulheres tem crescido, os preconceitos e estereótipos de gênero continua $m$ a tua ntes, e isso mesmo em países desenvolvidos como os Estados Unidos, com um importante histórico de partic ipa ção feminina na política.$^{21}$ As mulherescandidatas a cargos eletivos têm de enfrenta ro estereótipo que coloca os homens nos cargos de liderança política, reservando às mulheres o tra to dos problemas domésticos. Os homens têm tomado para si o papel principal na construção do que seja a política, do que faz um político e de qual a agenda para uma eleição. As candidatas mulheres têm assim de superar esse estereótipo, a presentando qua lida des nec essá rias para a lidera nça, sem, no enta nto, deixarem de se apresentar como mulheres: "Elas têm que apresentar força e assertividade sem parecerem masculinas". ${ }^{22}$

Nessa literatura que trata do estereótipo de gênero na política, um dos resultados que nos parecem ma is instig a ntes diz respeito a como as mulheres são a ssocia das mais imediatamente a estereótipos enquanto os homens não tra riam essa s marcas preconcebidas. Mesmo quando os eleito res sã o simpátic os à s c a nd id a tura sfeminina s, esses estereótip os a inda estã o presentes. ${ }^{23}$ Isso sina liza a presença de um discurso 'masculino' sobre as mulheres que vem sendo construíd o e mantido, enquanto que os homens são muita s vezes preserva dos de marcas disc rimina tória s. Como resultado, enquanto os homens têm um lugar social que garante a apresentação pública de suas idiossincrasias, as candidatas mulheres parecem sofrer do desconhecimento social sobre o que é ser uma mulher pública/política, estimulando a assunção de estereótipos cujas fontes primárias se encontram na mulher restrita à cena privada.

Sapiro ${ }^{24}$ indica, a inda, que a diferença de gênero está presente não a penas na distinção ma sculino-feminino, mas ta mbém na maneira como são percebidosesses traços nos candidatos, na expressão do gênero e mesmo no perfil dos cargos que estão sendo disputados, se eles requerem mais características 'femininas' ou ma is características 'masc ulinas'. A a genda associa da a o cargo e sua dimensão de gênero têm um claro impac to nas esc olhas dos eleitores, 
${ }^{25}$ Kim Fried kin KAHN, 1996, p. 132.

${ }^{26}$ SAPIRO, 1982.

${ }^{27}$ DOLAN, 2004. sendo a relação entre gênero e agenda política especialmente importante quando se tem pouca informação a respeito dos candidatos.

Em relaçã o à s espec ia lid a des de gênero a ssocia das a imagens estereotipa das, na sá rea sditas de espec ia lid a de feminina, como educação e saúde por exemplo, as mulheres são ma is bem a va lia das do que os homens, a lém de serem consideradas ma is honestas e sensíveis a o sofrimento das populações. ${ }^{25} \mathrm{Em}$ áreas de especialidade ma sculina, por outro la do, a depender das condições da eleição (o cargo a ser ocupado, o conhecimento dos eleitores sobre o candidato e a agenda da eleição), homens candida tos podem ser ma is bem a va lia dos e terem maior chance de vitória. Em pesquisa sobre as diferenças de gênero nas candidaturas a cargos legislativos nos Esta dos Unidos, as candida tas são bem a valia das mesmo quando os tópic os são ma is nitidamente masculinos, como segurança e economia. ${ }^{26}$ No entanto, ainda quando avaliadas no mesmo patamardos candidatos masculinos, as c a nd id a tura sfeminina s sã o referid a s pelos suje ito s como tendo menos chances de ganhar as disputas. Isso sugere que não se estaria avaliando o quesito competência, mas os lugares que devem serocupa dosporhomense mulheres no espaço público. É como se a mensagem transmitida poresses sujeitos fosse que as mulherespodem oc uparesses lugares. Mas não devem. A questão importante sugerida por esses estudos é que as candid a ta s feminina s enfrentam um peso de serem mulheres que não pode ser explic ado ou contra-a ta ca do - pela razão, exigindo dela sum esforço maior para serem aceitas como ocupantes efetivas de cargos de liderança.

Poroutro lado, o trabalho de Ka theen Dola $n^{27}$ sobre as eleiçõesamericanasdurante a década de 1990 lembra que a questão de gênero não pode ser apontada como única variável na escolha de um candidato. Ao contrá rio do que muitos outros estudos p retendem demonstra $r$, o sexogênero da candidata não afeta todos os eleitores da mesma forma, e seu impacto depende do candidato, seu partido, do eleitore do meio. A escolha ta mbém depende das características do próprio eleitor: seu próprio gênero, sua escolaridade, seus valores e interesses que ele irá reconhecer - ou não - em um determinado candidato. Segundo Dolan, o efeito do gênero em uma eleição não tem valor em si, mas depende de outras variá veis, como por exemplo o fato de o estereótipo de gênero estar associa do a outros estereótipos como os associados a um partido político e à sua ideologia.

Ainda assim, seria possível dizer que, embora a escolha não se faça pelo sexo do candidato, ela parece 
${ }^{28}$ Lynette UTHG OW, 2000.

${ }^{29}$ KAHN, 1996.

${ }^{30}$ ANSO LABEHERE, BEHR e IYENG AR, 1993.

${ }^{31}$ KAHN, 1996.

32 HELDMAN, CARROL e OLSON, 2000.

${ }^{33}$ KAHN, 1996. estar relacionada ao discurso que ele porta - que pode ser, inclusive, antagonista do seu gênero: um discurso masculino em um 'corpo' feminino. ${ }^{28}$

Junto à presença de estereótipos sexuais entre os eleitores e a agenda política para uma determinada eleição e cargo, elementos dinâmicos que conduzem à percepção dos candidatos pelos eleitores e a uma escolha, ${ }^{29}$ salientam-se a estratégia contida nas propagandas dos candidatos para lidar com esses fa tores e a cobertura da mídia.

Nessas condições, a mídia teria um papel preponderante, podendo provocarqua tro diferentes efeitos nas campanhas eleitora is: fomecer informações, definir a agenda política, definir responsabilidades e, finalmente, persuadir o eleitor. ${ }^{30}$ Quanto maior e mais focada for a cobertura da mídia, como é o caso, por exemplo, de eleições para cargos executivos, maior a influência do gênero sobre a decisão dos eleitores. A cobertura da mídia tem também importância significativa na transforma ção doscandidatos. Geralmente, ela é ma is deprecia tiva para as cand ida tura femininas, distorc endo as mensagens das mulheres, ${ }^{31}$ e é um fator preponderante na influência dos eleitores a favor das candidaturas masculinas em detrimento dascandidaturasfemininas. Esse papelda mídia seria determina do pelo destaque que é oferecido àsáreas de segurança e economia, ditas de especialidade 'masculina', geralmente apresentadas pela mídia como mais importantespara a escolha de um candidato do que aquelas de apelo 'feminino' - e social - como saúde e educação. Mas esse papel diz respeito também a como uma candidata pode serma is predominantemente descrita em termos de sua vida pessoal, a parência e personalidade do que um candida to homem. ${ }^{32}$

Vale notar que, embora os estereótipos de gênero contaminem eleitores, candidatos e a cobertura da imprensa, eles nem sempre são handicaps, mas podem ser toma dos pela s cand id a ta s como va nta gens em função da agenda de uma determinada eleição em que são privilegiadas as áreas de conhecimento usualmente associadas às mulheres. ${ }^{33} \mathrm{O} u$ a inda, quando associa dos a o utras característic as das candidatas, como serem herdeiras legítimas de grupos familiares e de lideranças masculinas. Assim tem sido na escolha recorrente de 'viúvas' para ocuparos postos de comando máximo em diferentes países a siáticos, como nas Filipinas (Corazon Aquino) e no Sri La nka (Chandrika Kumaratunga). Nesses casos, a mídia realiza um papel importante na sustentação dos estereótipos que colaborariam para a instalação e 
${ }^{34}$ UTHG OW, 2000.

35 Marc VENKATESAN e J ean P. LOSC O, 1975.

${ }^{36}$ Cláudia FINAMORE, Adriana SALVIO, Angelina DAL CORTIVO, Sonia GIANETI e João Eduardo Coin de CARVALHO, 2002. manutenção de mulheres que não são lideranças mas continuadoras das obras de seus pais, irmãos e maridos. ${ }^{34}$

\section{Propaganda eleitoral: gênero e estereótipo}

Historic a mente, a imagem das mulheres veic uladas através de propagandas dos mais diferentes objetos de consumo se mantém associada a uma posição de subordinação, ${ }^{35}$ o que não parece ter mudado signific a tivamente nas últimas décadas. Ma is do que isto, a propaganda polític a parece tero efeito de desqualificar o candidato, o que, em determinadas circunstâncias, poderia ser ampliado pelo efeito de gênero. ${ }^{36}$

Para entender esse quadro, justapomos a importância dos estereótipos femininos como orienta dores da construção da imagem das candidatas a cargos eletivos. É importante considerar, antes de ma is nada, que os a utores que têm disc utido essa s ma rc as soc ia is no â mb ito das escolhas eleitora is as têm tra ta do a partir do conc eito de estereótipo. Como traços identitários que resistem a se transformar a o longo do tempo, os estereótipos são decisivos nas nossas escolhas. Mas, embora a idéia de estereótipo seja útil para compreender determinados fenômenos socia is, ela pode trazer consigo uma tendência à sua natura lização. Dessa forma, é importante considerar, no processo de construção dessas imagens coletivas, as condições nas quais os estereótipos são produzidos e mantidos, levando em conta os condicionantes sóciohistóric os e imaginários que estão presentes nos processos de categorização, no centro das relações intergrupos e na constituição das identida des socia is. Considerar esses condicionantes reflete-se aqui na importância dada aos discursos sobre as mulheres, sobre os políticos e sobre a mídia e à dinâmica dessas inter-relações.

\section{Participação da mulher no processo eleitoral brasileiro}

Embora a análise dessa oposição entre o público e o priva do e suas rela ções de gênero venha sendo discutida na literatura sobre o assunto no Brasil, ela não tem logrado alcançar com mais propriedade como as diferenças relacionadas ao gênero melhor situariam a posição da mulher, mesmo no âmbito priva do, como partic ipa ntes dos processos políticos. ${ }^{37}$

No quadro brasileiro, enquanto se debate o veto da c lasse domina nte à partic ipação das mulheres na política, esse confronto mulher-política pode seracompanhado no dia-a-dia, pela influência dos discursos sobre a mulher e 
${ }^{38}$ Ruth SABAT, 2001; e Tânia SWAIN, 2001.

${ }^{39}$ Clara ARAÚj O, 2001.

${ }^{40}$ ARAÚj O, 2001, p. 239.

${ }^{41}$ Eros DESO UZA, J ohn BALDWIN e Francisc o DA ROSA, 2000. sobre os polític os que circulam entre os grupos socia is. Isso pode ser visto nos jomais diários, na cobertura televisiva dos fatos econômicos e políticos que têm 'figuras masculinas' como seus protagonistas, ou na presença maciça das mulheres nos noticiários de entretenimento e na sua 'visibilidade' conferida nas revistas 'femininas' e 'masculinas' que inundam as bancas de jomais, ou ainda na propaganda. ${ }^{38}$ Nesse cenário, não bastaria a mera presença da mulher entre os candidatos, sustentada por uma política de cotas, para transformara posição que ela ocupa ali, embora essa presença seja necessária para a rtic ular qualquer mudança. Antes, a presença da mulher nos qua drospartidáriose nascandida turasa cargos eletivos deve estar associada àquelas imagens da mulher e do político que hoje são predominantes e, via de regra, conflitantes na nossa sociedade.

A baixa participação das mulheres no plano polític o não deve ser entendida como resulta do de seu desinteresse ou apenas de um veto de gênero por parte dos partidos. Essa partic ipação tem como um de seus vetoreso confronto entre os diferentes trajetos usualmente percorridos pelas mulheres e a maneira como se faz política no país. ${ }^{39}$ Ao lado da importância dos "cálculos de racionalidade instrumental e estra tégica dospartidos frente a o sistema", ${ }^{40}$ a "resistência masculino-partidária" não é um fator desprezível ao se procurar entender a participação das mulheres na política. Nesse sentido, Clara Araújo indicou a importância de associar as características do modelo polític o nacional com a s questões tra diciona Imente liga das à exclusão feminina no â mbito do preconceito de gênero. Se evidenciamos aqui essa resistência, é tratando de posicioná-la não no quadro da razão, mas na tensão que parece existir entre os papéis público e privado ocupados pela mulherna nossa sociedade. 0 papel reservado para as mulheres na política parece dever se equilibrar, como de resto todas as mulheres dedicadas às duplas jomadas de seu trabalho remunerado e às "tarefas do dia-a-dia" sabem reconhecer, entre de um lado ser o político (pragmático, malicioso, individualista) e de outro ser a mulher (mãe, dona-de-casa, preocupada com a família). Este último é o papel de Maria construído para a mulher desde o descobrimento do Brasil, como sendo a mulher mártir, submissa aos homens, resultado de um machismo que entende os homens como mandatários natura is do governo e da atividade pública ${ }^{41}$

Em uma campanha política, evidentemente, esse confronto pode ser acirrado ou suavizado em função do andamento da campanha sem compromisso com a 'verdade' sobre uma determinada candidata. O teor das 
${ }^{42}$ KAHN, 1996.

${ }^{43}$ Mala HTUN, 2001.

${ }^{44}$ MIGUEL, 2002.

${ }^{45}$ CARVALHO, 1999. propagandas, se de ataque aos adversários ou de valorização das suas próprias qualidades, se propositivo de uma agenda mais ou menos feminina, terá tido assim seu papel na imagem construída e veiculada pelas candidatas, como outras pesquisas têm demonstra do. ${ }^{42} \mathrm{E}$ isso tem sido utilizado, em maior ou menor escala, pelas candidatas a cargos políticos, o que pode ser consta ta do a tra vés do desempenho histórico das mulheres candidatas a cargos eletivos, que, de fato, vem, mesmo que vagarosamente, melhorando ao longo do tempo, tendo sofrido um expressivo crescimento durante a década de 1990.43

Não se trata, portanto, de estabelecerse as verdades sobre as candidatas são a presentadas e assimila da s pelo eleitorado, mas de verificar o quanto o confronto entre diferentes discursos está presente no posicionamento dos indivíduos e dos grupos socia is. Não se vai duvidar da importância da mídia na configuração de uma campanha eleitoral, mas ela não deve ser entendida como a única vilã da disputa, e sim como amplificador de discursos que estão circulando entre os grupos socia is, conformando as identida dessocia is e o próprio universo simbólico onde estes grupos existem. Se os eleitores, tal qual acredita Miguel, ${ }^{44}$ analisam e refletem sobre a campanha política, não absorvendo pacific amente as informa ções veiculadas na TV, isso se dá em um a mbiente mediado por forças que estão presentesnão a penasna propaganda eleitoral, mas mesmo fora dela. A ação da mídia sobre essas forças, flexionando esses disc ursos, possibilita um movimento sobre a ima gem dascandidatas femininas, masnã o é a sua únic a matriz. O discurso que circula inclusive pela mídia a antecipa na expressão de conceitos e imagens, inclusive sobre os grupos/categorias sociais. A mídia participa na criação de um certo discurso, a tuando ma is propriamente na sua modulação. Interferindo no seu fluxo, a mídia a umenta certos 'tons' e deixa outros ina udíveis, produzind o sobre esses discursos um efeito secundário. ${ }^{45}$

O exemplo da ex-prefeita Marta Suplicy, candidata derrotada à reeleição para a Prefeitura de São Paulo em 2004, é emblemático. Possuidora de uma imagem sofistic ada, inteligente, professora universitária, ligada a uma das mais tradiciona is famílias paulistanas, isto é, a imagem da mulher produzida por um discurso eminentemente masculino, vinha se contrapondo, desde antes da sua primeira eleição em 2000, à imagem de a lguém de ação, política, interessa da em ocuparum papel social notadamente 'masculino', isto é, a imagem do político. 
46 FINAMORE, SALVIO, DAL CORTIVO, GIANETII E CARVALHO, 2002.

${ }^{47}$ David FLEISC HER, 2002.
$\mathrm{Na}$ iminência das eleições munic ipa is bra sileiras de 2000 investigamos a influência da propaganda eleitoral gratuita sobre a campanha da então candidata Marta Suplicy. ${ }^{46}$ A pesquisa avaliou se e como a propaganda eleitoral gra tuita disseminada a tra vés da TV influenciaria o eleitor em relação à imagem da candidata, entrevistando eleitores antes de assistirem à propaganda eleitora I gra tuita e, novamente, após assistirem a cinco dias consecutivos de propaganda.

Enquanto nas primeiras entrevistas, antes de os pesquisados assistirem à propaganda eleitora I gratuita, a candidata detinha um conceito positivo como mulher atuante na política, apresentando qualidades que a a uxiliariam na ocupação do cargo de prefeita, ta is como sensibilidade para os problemas sociais, bom senso para administração e perfil a dequado a o cargo executivo, nas entrevistas realizadas após os sujeitos assistirem à propaganda eleitoral, apenas alguns dias depois das primeira s entrevistas, a imagem da candidata à Prefeitura sofreu uma mudança bastante signific ativa nos relatos dos sujeitos. Percebida como um efeito de marketing, a ima gem da candidata veiculada na mídia perdeu legitimida de por a dquirir um caráter falsa mente construíd o.

Naquela oportunidade, a exposição na mídia televisiva mostrou a guçaruma contra dição entre estes do is papéis, da mulher e do político, o que não foi suficiente, no entanto, para impedir a vitória da candida ta, tendo em vista a dinâmica do processo eleitoral e as diferentes forças polític as presentes no confronto com os outros candida tos. ${ }^{47}$ Nessa segunda oportunidade, mais do que mero 'efeito' da mídia sobre o eleitorado, sua derrota pode ser compreendida, também, no a cirramento do confronto entre discursos, nos quais a imagem da mulher é coteja da com a imagem do político, o que ampliaria a sensação pelos eleitores de esta rem sendo duplamente 'enganados', por uma mulherque age como um político.

A mídia tem papel fundamental na disseminação das representações da realidade sócio-econômica e da imagem das mulheres, e dos políticos, influenciando a forma ção da op iniã o pública em diferentes circ unstâncias, inclusive durante o processo eleitoral. Entendemos, no cenário complexo onde se constroem as escolhas dos eleitores, como é preciso buscar os determinantes políticos na disseminação e ma nutenção de determina dos discursos através da mídia televisiva, especialmente no caso brasileiro. A prevalência da imagem que crista liza o papel de Maria mantém a mulher contida no âmbito privado e a 
apresenta como um produto de consumo. Assim, a inda que se possa intervirglobal e instituciona lmente, buscando argumentos que sustentem a razoabilidade da mudança do papel da mulher, entendemos que no âmbito do cotidiano se poderia implementarações de guerrilha que a tacariam os discursos hegemônicos sobre a mulher, discursos esses entranhados tanto entre homens quanto entre as próprias mulheres.

Dessa forma, julgamos necessá rio dar a tenção a como é feita a construção cotidiana desses discursos hegemônicos atra vés de todos os meios que alcançam o senso comum. As conversas do dia-a-dia, a sua presença na mídia 'não informativa', como novelas, programas humorístic os ou revistas de entretenimento, e o uso que se faz dessa imagem na propaganda contribuem para normatizar a imagem sobre as mulheres que atra vessam nossa sociedade. A disc ussão e a crític a constante, e não apenas em época de eleição, à presença desses entendimentos reificados no senso comum, utilizando ferramentas que pudessem interferir nas suas dimensões imaginárias através da própria mídia, é o que poderia garantir a presença efetiva de um discurso efetivamente feminino no âmbito político.

\section{Referências bibliográficas}

ANSO LABEHERE, Stephen, BEHR, Roy, and IYENGAR, Sha nto. The Media Game: Americ an Politic s in the Television Age. New York: Mcmillan, 1993.

ARAÚJ O, Clara. "Potencialidades e limites da política de cotas no Brasil". Revista Estudos Feministas, v. 9, n. 1, p. 231-52, 2001.

AZAMBUJ A, Darcy. Introdução à ciência política. 6. ed. Rio de Janeiro, Globo, 1987.

BLANCO, Vic tor Fra nc isc o Sa mpedro. "Efec tos de los médios de comunicación sobre la opinión pública: los paradigmassobre el poder del público". Comunic ação \& Política, v. 6, n. 1, p. 129-155, 1999.

BRITO, Maria Noemi Castilhos "Gênero e cidadania: referencia is a na lític os". Revista Estudos Feministas, v. 9, n. 1, p. 291-298, 2001.

BURREL, Barbara C. A Woman's Place is in the House: Campaigning for Congress in the Feminist Era. Ann Arbor: University of Michigan Press, 1994.

CARVALHO, João Eduardo Coin de. Grupos-nome e identidades adolescentes: uma proposta de entendimento para a virtualização do cotidiano. 1999. Tese (Doutora do em Psicologia) - Universidade de São Paulo. 
"Os grupos-nome: os efeitos da substituição do ima ginário pelo virtual na constituição dos grupos sociais". Psicologia e Sociedade, v. 14, n. 1, p. 28-43, 2002.

CASTORIADIS, Cornélius. A instituição imaginária da sociedade. Rio de Janeiro: Paz e Terra, 1995.

COIMBRA, Cecília M. B. "Mídia e produção de modos de existência". Psicologia: Teoria e Pesquisa, v. 17, n. 1, p. 1-4, 2001.

CONWAY, Ma rga reth, STEUERNAGEL, G ertrude A., a nd AHERN, David W. Women \& Political Participation: Cultural Change in the Political Arena. Washington: CQ Press, 1997.

DESOUZA, Eros; BALWIN, J ohn R.; DA ROSA, Francisco Heitor. "A construção social dos papéis sexua is femininos". Psic ologia: Reflexão e Crítica, v. 13, n. 3, p. 485-496, 2000.

DOLAN, Kathleen. Voting for Women: How the Public Evaluates Women Candidates. Boulder: Westview Press, 2004.

FINAM ORE, Clá udia; SAVIO, Adria na; DALC ORTIVO, Ang elina S.; GIANETT, Sonia R.; CARVALHO,

J oão Eduardo Coin de. A representação social da candidata Marta Suplicy pelos eleitores de São Paulo. In: CONGRESSO BRASILEIRO PSICOLOGIA: CIÊNCIA E PROFISSÃO, 1., 2002. Ana is... São Paulo, 2002.

FLEISC HER, David. "As eleições municipa is no Brasil: uma a nálise comparativa (1982-2000)". Opinião Pública, v. 8, n. 1, p. 80-105, 2002.

HELDMAN, Ca roline, CAROLL, Susan J., and OLSON, Stephanie. Gender Diferences in Media Print Coverage of Presidential Candidates: Elizabeth Dole's Bid for the Republican Nomination. Annual Meeting of the American Political Society Association. Washington, 2000. [Disponível em: www.rci.rutgers.edu/ cawp/Research/ Reports/dole.pdf. Acesso em: 23 jul. 2005.]

HTUN, Mala. "A polític a de cotas na Améric a La tina". Revista Estudos Feministas, v. 9, n. 1, p. 225-230. 2001

KAHN, Kim Friedkin. The Political Consequences of Being a Woman: How Stereotypes Influence the Conduct and Consequences of Political Campaigns. New York: Columbia University Press, 1996.

LEEPER, Mark Stephen. "The Impact of Prejudice on Female Candidates: an Experimental Look at Voter Inference". American Politic s Quarterly, v. 19, n. 2, 1991. p. 248-261.

UTHGOW, Lynette. A Question of Rela tivity: The Role of the News Media in Shaping the View of Women in Asian Political Dyna sties. 2000. [Disponível em: www.ksg.harvard.edu/ presspol/Research_Public a tions/Pa pers/Working_Pa pers/ 2000_13.PDF. Acesso em: 1 dez. 2005.] 
MIGUEL, Luis Felipe. "Míd ia e ma nipula ção polític a no Bra sil: a Rede Globo e as eleições presidenciais de 1989 a 1998". Revista Comunicação \& Política, v. 6, n. 1, p. 119-138, 1999.

- "Retrato de uma ausência: a mídia nos relatos da história política do Brasil". Revista Brasileira de História, v. 20, n. 39, p. 191-199, 2000.

- "Os meios de comunicação e a prática política". Lua Nova: Revista de Cultura e Política, v. 55-56, p. 155$184,2002$.

SABAT, Ruth "Pedagogia cultural, gênero e sexualidade." Revista Estudos Feministas, v. 9, n. 1, p. 4-21, 2001.

SAPIRO, Virginia. "If Senator Baker Were a Woman: an Experimental Study of Candidate Images". Political Psychology, v. 3, 1982. p. 61-83.

SC HMITT, Rog ério; CARNEIRO, Leandro P.; KUSC HNIR, Ka rina. "Estratégias de campanha no horário gratuito de propaganda eleitoral em eleições proporciona is". Dados [on line], v. 42, n. 2, 1999. Disponível em: http:// www.sc ielo.br/scielo.php?script=sci_arttext\&pid = S0011$52581999000200003 \& \mathrm{lng}=\mathrm{en}_{\mathrm{n}} \mathrm{nrm}=$ iso. Acesso em: 23 jul. 2005.

SWAIN, Tania N. "Feminismo e recortes do tempo presente: mulheres em revistas 'femininas'". São Paulo em Perspectiva, v. 15, n. 3, p. 67-81, 2001.

SWERS, Mic hele. "Understa nding the Polic y Impa ct of Elec ting Women: Evidence from Research on Congress and State Leg isla tures." Politic al Sc ience \& Politic s, v. 34, n. 2, 2001. p. 217-220.

THOMPSON, J ohn B. Ideologia e cultura moderna. Petró polis: Vozes, 1989.

VENKATESAN, Marc, and LOSCO, J ean P. "Women in Magazine Ads: 1959-71". Journal of Advertising Research, v. 15, n. 5, 1975. p. 49-54.

[Recebido em julho de 2005 e aceito para publicação em fevereiro de 2006]

\section{Women Candidates: Gender, Media and Discourse Relations}

Abstract: On this paper we discuss, within the cross over of two representations - woman and politic function - the media's power to influence voters' choices and their roles as interpreters of media messages. Under a position that understands the relativity of the media's power, we set the idea of gender discourse as a mediator of its influence. Whereas literature shows how a candidate suffers an important effect of media exposition, transformed in a marketing product, we suggest that women in politics suffer from the stereotype that states "women's place is at home". We conclude that women politic participation is strongly linked to the way in which they are represented in the common sense and a change in the hegemonic discourses about women that cross individuals and social groups becomes necessary as to have this situation modified. Key Words: Gender; Politic s; Elections; Disc ourse; Media. 